\title{
Electrochemically Synthesized Nano-photocatalysts for Photodegradation of Organic Compounds
}

\author{
Murodjon Abdukhakimov, Ilnur Garipov, Atabek Yuldashev, Olga Gapurova, Ildar Galiulin, \\ Ilkham Sadikov, Rashid Khaydarov, Renat Khaydarov*"
}

Laboratory of Interdisciplinary Technologies, Institute of Nuclear Physics, Tashkent, Uzbekistan

\author{
Email address: \\ renat@inp.uz (Renat K.) \\ *Corresponding author
}

\section{To cite this article:}

Murodjon Abdukhakimov, Ilnur Garipov, Atabek Yuldashev, Olga Gapurova, Ildar Galiulin, Ilkham Sadikov, Rashid Khaydarov, Renat Khaydarov. Electrochemically Synthesized Nano-photocatalysts for Photodegradation of Organic Compounds. Chemical and Biomolecular Engineering. Vol. 5, No. 3, 2020, pp. 57-61. doi: 10.11648/j.cbe.20200503.11

Received: September 24, 2020; Accepted: October 9, 2020; Published: October 30, 2020

\begin{abstract}
Over the last decades, extensive studies have been carried out on nano-photocatalytic materials finding a broad range of applications mainly in solar energy conversion and environmental remediation. This article focuses on synthesizing a novel nano-photocatalyst material for purifying water from chloro-organic pollutants and microbes. It was synthesized in the electrolytic cell with titanium and graphite electrodes. TEM analysis revealed that the obtained nanocarbon-titanium composite has a spherical morphology, the average dimension of nanoparticles is $6 \pm 2 \mathrm{~nm}$. The electrochemically synthesized nano-photocatalyst forms $\mathrm{OH}$ radicals in the presence of water vapor during daylight hours under sunlight's ultraviolet radiation. As soon as extremely reactive $\mathrm{OH}$ radicals are formed, they react with organic pollutants. The results of photodegradation of $E$. Coli, methyl orange, methyl blue, and polychlorinated biphenyls in the ultraviolet spectrum of sunlight have been discussed. The effect of $\mathrm{pH}$ value on the decolorization efficiency has been also observed. The obtained photodegradation time of methyl orange $(\mathrm{MeO})$ and methyl blue (MeB) solutions was less than 60 minutes, and the destruction time of polychlorinated biphenyl (PCB) compounds was about 6-8 hours. The practical application of the developed nano-photocatalyst material promises to be an inexpensive, viable alternative or complimentary method for water and wastewater treatment at ambient temperature to degrade various chemical and microbiological pollutants in water.
\end{abstract}

Keywords: Nano-Photocatalyst, Photocatalysis, Organic Substance, Sunlight

\section{Introduction}

Photocatalysis based on nano-catalysts is a very promising method for the treatment of contaminated water. Both solar photocatalysis and photocatalytic systems equipped with artificial ultraviolet (UV)-light systems can be applied at ambient temperature to degrade various chemical and microbiological pollutants in water and air: organic materials, organic acids, estrogens, pesticides, dyes, crude oil, microbes (including viruses and chlorine resistant organisms), inorganic molecules such as nitrous oxides $\left(\mathrm{NO}_{\mathrm{x}}\right)$ and, in combination with precipitation or filtration, can also remove metals (such as mercury) [1]. There are several potential photocatalysts, but the most widespread substance is nanotitanium dioxide. Nano-sized particles are preferred to bulk $\mathrm{TiO}_{2}$ because they are significantly more reactive than larger particles due to their larger surface area. $\mathrm{TiO}_{2}$ is chemically stable and has a high ability to break molecular bonds leading to degradation. To avoid free nanoparticles in water, nano- $\mathrm{TiO}_{2}$ particles are usually immobilized on a substrate or integrated into thin-films and other materials [2]. But the lifetime of nanoparticles before their agglomeration can be easily regulated [3]; this allows removing particles from water or air in required time. This method opens an opportunity to increase efficiency of catalysts significantly by using colloidal nano-photocatalysts homogeneously dispersed in water or air to be treated. Moreover it is important to develop new types of nano-photocatalysts with 
enhanced catalytic properties. This paper describes a new technology for destruction of bacteria and organic substances which is based on usage colloidal nanocarbon-metal compositions (NCMC) as nano-photocatalysts.

\section{Principle of the Method}

The principle of the method is based on destruction of organic substances and bacteria by nano-photocatalysts (NPC) dispersed on polluted open land or water. These nano-photocatalysts under natural ultraviolet radiation form $\mathrm{OH}$-radicals in presence of water molecules and the radicals destroy decompose organic substances and bacteria. In brief, photocatalytic reactions of aqueous NPC suspension system can be described as follows [4]:

$$
\begin{gathered}
\mathrm{NPC}+\mathrm{h} v \rightarrow \mathrm{NPC}+\mathrm{e}_{\mathrm{CB}}^{-}+\mathrm{h}^{+} \mathrm{VB} \\
\mathrm{h}_{\mathrm{VB}}^{+}+\mathrm{OH}^{-}(\text {surface }) \rightarrow \mathrm{OH}^{\cdot} \\
\mathrm{h}_{\mathrm{VB}}^{+}+\mathrm{H}_{2} \mathrm{O} \rightarrow \mathrm{OH}^{\cdot}+\mathrm{H}^{+} \\
\mathrm{e}_{\mathrm{CB}}^{-}+\mathrm{O}_{2} \rightarrow \mathrm{O}_{2}^{-} \\
\mathrm{e}_{\mathrm{CB}}^{-}+\mathrm{h}_{\mathrm{VB}}^{+} \rightarrow \text { heat }
\end{gathered}
$$

where $\mathrm{h} v$ is the $\mathrm{UV}$ irradiation, $\mathrm{h}_{\mathrm{VB}}^{+}$is valence-band holes, and $\mathrm{e}^{-}{ }_{\mathrm{CB}}$ is the conduction-band electrons. It is known that active oxygen and radical species existing in the presence of oxygen and water take part in the oxidation-reduction reaction and destroy decompose organic molecules and bacteria [5]. The nano-photocatalysts must be harmless; their concentration in water must be lower than permissible level; and nanoparticles must form agglomerates during required time, coagulate and precipitate, i.e., must form safe ordinary particles. Many semiconductive metal compounds are used as the photocatalysts and the most known among them is $\mathrm{TiO}_{2}$. Usually photocatalysts are applied on a carrier, have sizes more that $1 \mathrm{um}$ and cannot be used for dispersion on a large area. That is why it is necessary to develop new type of nano-photocatalyst which can meet all described above requirements. As well known, nanocomposites combine the properties of two or more different materials with the possibility of novel mechanical, physical or chemical behavior arising [6]. Nanocomposites of conjugated materials and metal nanoparticles are prepared from different metals, different types of conjugated polymers and oligomer linkers [7, 8]. Another type of nanoscale materials are nanocomposites of carbon nanoparticles and polymers. Indeed, for example, electrolytically generated nanocarbon colloids (NCC) have functional groups such as carbonyl, hydroxyl and carboxyl groups formed on the surface of carbon nanoparticles $[9,10]$. These nanocomposites can be modified by attaching different cations. On the other hand, most of polymers can react with different ions and molecules and also participate in modification of nanocomposites, for example, like nanocarbon-polymer nanocomposites (NCPC) prepared via electrolytically generated NCC and polyethylenimine PEI [3]. A similar method can be used to prepare nanocarbon-metal nanocomposites (NCMC) as the nano-photocatalysts to control cyanobacteria.

\section{Materials and Equipment}

Nanocarbon-metal nanocomposites with titanium as the metal NCMC (Ti) were prepared by the electrochemical method. The process was based on the use of two-electrode device $[11,12]$ in which one electrode was made of a high-density isotropic graphite OEG4 (Russia) and the second electrode was made of titanium plate. The electrodes were immersed in a plastic electrolytic cell filled with $0.025 \mathrm{M} \mathrm{H}_{2} \mathrm{SO}_{4}$ as the electrolyte. The process of device operation involved 2 repeatable consecutive steps: 1) the electrolysis during 2-10 min when Ti-electrode was as an anode, 2) the electrolysis during 2-5 min when carbon electrode was as an anode. The size and the shape of nanoparticles were determined with transmission electron microscopy (TEM) (LEO-912-OMEGA, Carl Zeiss, Germany). Concentration of $\mathrm{Ti}$ in solutions was determined by neutron activation analysis by irradiating water samples in the Nuclear Reactor of the Institute of Nuclear Physics (Tashkent, Uzbekistan). The photocatalytic oxidation of methyl orange $(\mathrm{MeO})$ and methyl blue $(\mathrm{MeB})$ in NCMC (Ti) suspension under UV illumination was investigated in order to evaluate the photocatalytic activity of the nanoparticles. A $150 \mathrm{ml}$ of a $3.2 \times 10^{-3} \mathrm{~mol} / 1 \mathrm{MeO}$ and $\mathrm{MeB}$ solutions were filled into a Petri dish. A $60 \mathrm{~W}$ UV lamp (DB-60, Russia) fixed at a distance of $25 \mathrm{~cm}$ above the solution surface was used as the UV light source and provided radiation power of $1 \mathrm{~W} / \mathrm{m}^{2}$ in the interval from $220 \mathrm{~nm}$ to $320 \mathrm{~nm}$. The absorbance of the $\mathrm{MeO}$ and $\mathrm{MeB}$ solutions were measured with Cary 50 UV-Vis spectrophotometer (Varian) with Xenon flash Lamp. Experiments with bacteria were conducted with culture E. Coli (272) in temperature range $18-36^{\circ} \mathrm{C}$. The cultivation, culture enrichment, the testing bacteria were performed following the Standard Methods (USSR, Russia) for Testing Chemical Procedures (Drinking Water. Hygiene requirements and quality control 1982) for the evaluation of disinfection [13]. PCBs from transformer ("transformers oil") were used. The analysis of PCBs was performed by GC/MS (Agilent Technologies $6890 \mathrm{~N}$ network gas chromatography system with 5973 inert MSD) operating in SIM mode. The PCBs were separated using a DB-5 (60 m, $0.25 \mathrm{~mm}, 0.25 \mathrm{~lm})$ chromatographic column.

\section{Results and Discussion}

Experiments have shown that yield of NCMC (Ti) in electrolysis process depends on voltage $\mathrm{V}$ between electrodes and $\mathrm{pH}$ of solution. Figure 1 shows that the yield $\mathrm{dC}_{\mathrm{Ti}} / \mathrm{dt}$ of $\mathrm{Ti}$ in 6 minutes after beginning the electrolysis process, where $\mathrm{C}_{\mathrm{Ti}}$ is the concentration of $\mathrm{Ti}$ in the electrolyte, increase with increasing voltage between electrodes up to $12-13 \mathrm{~V}$ but then decrease slowly. This behavior is explained by formation of three - valence titanium on the surface of Ti-electrode, the electrode becomes of blue color. Figure 2 demonstrates 
dependence of $\mathrm{dC}_{\mathrm{Ti}} / \mathrm{dt}$ against the concentration of $\mathrm{H}_{2} \mathrm{SO}_{4}$ in the solution in 6 minutes after beginning the electrolysis process. When $\mathrm{pH}$ of the electrolyte closes to neutral value three - valence titanium is formed on the surface of the Ti electrode.

During the first stage of the electrolysis process when Ti-electrode is the anode, electric current between electrodes is about 3-4 $\mathrm{mA} / \mathrm{cm}^{2}$. In the second stage after changing the polarity electric current increases up to $180-200 \mathrm{~mA} / \mathrm{cm}^{2}$ in about 0.1-0.2 second. During the first stage oxygen is released on the titanium anode, titanium oxides and sulfates are formed on the surface and titanium ions leaved the anode are oxidized by oxygen near the surface of anode in the solution or react with NCC which has carboxyl groups as the active groups. The thin semiconductor layer formed on the surface of the titanium electrode has high resistance and electric current between electrodes is small, about $3-4 \mathrm{~mA} / \mathrm{cm}^{2}$. At the same time the negatively charged carbon nanoparticles go away from the graphite cathode and the functional groups such as carbonyl $(>\mathrm{C}=\mathrm{O})$, hydroxyl $(-\mathrm{OH})$, and carboxyl $(-\mathrm{COOH})$ group are formed on the surface of carbon particles. During the second stage oxidation process is occurred at the carbon anode. The magnitude of repulsion forces formed between the stacked layers of graphite gets larger than that of van der Waals attraction forces between the layers, preparing a condition for formation of carbon nanoparticles when polarity of electrode will be changed. The surface of the titanium cathode is cleaned from the oxides and electric current between electrodes increases up to $180-200 \mathrm{~mA} / \mathrm{cm}^{2}$. Titanium ions and charged particles of titanium oxide interact with carbon nanoparticles and form NCMC (Ti) [14]. Oxygen adsorbed on the surface of particles forms $\mathrm{Ti}(\mathrm{OH})-\mathrm{O}-\mathrm{Ti}(\mathrm{OH})-$, which can help the photogenerated holes $\mathrm{h}^{+}$to change into $\mathrm{OH}^{*}$ free radical $[3,15]$. Otherwise, the oxidization activity of $\mathrm{OH}^{*}$ is the strongest in aqueous solution [16]. Typical TEM micrograph of NCMC (Ti) is given in Figure 3 and shows that nanoparticles have a spherical morphology. Measurements of particles sizes have shown that average dimension of nanoparticles is $6 \pm 2 \mathrm{~nm}$.

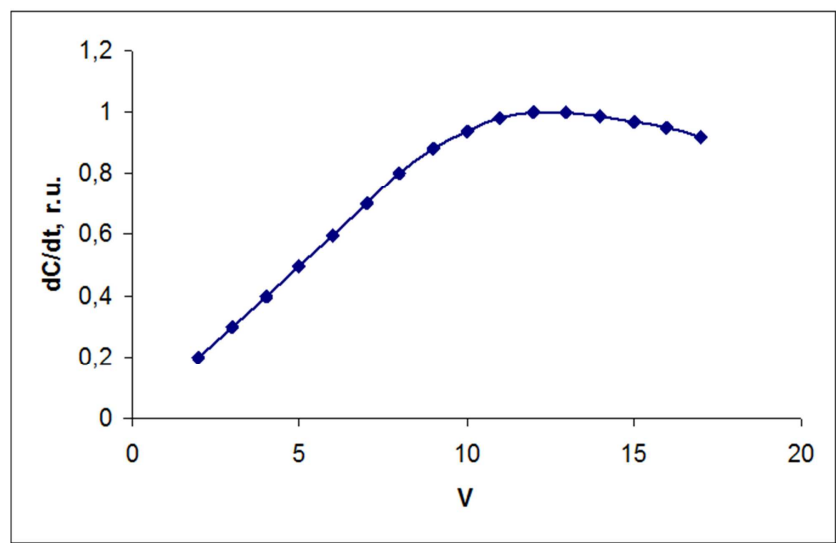

Figure 1. Dependence of the yield of titanium in six minutes after beginning the electrolysis process against electrolysis voltage.

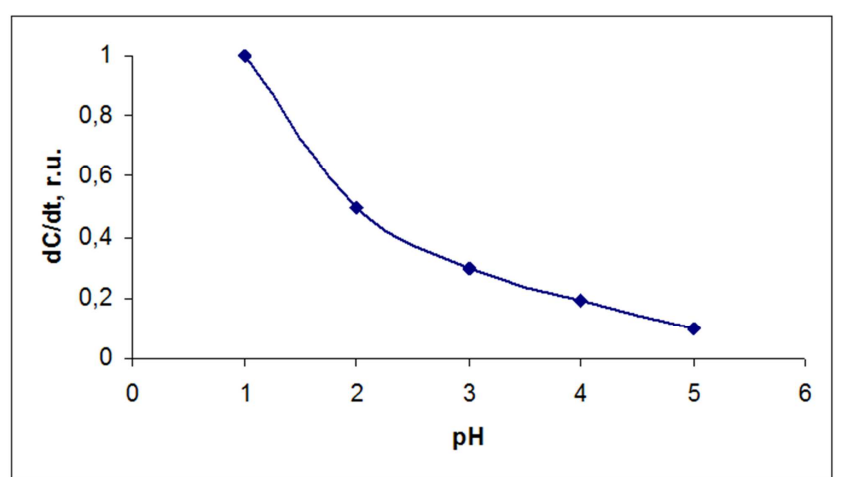

Figure 2. Dependence of the yield of titanium in six minutes after beginning the electrolysis process against $\mathrm{pH}$ of the solution.

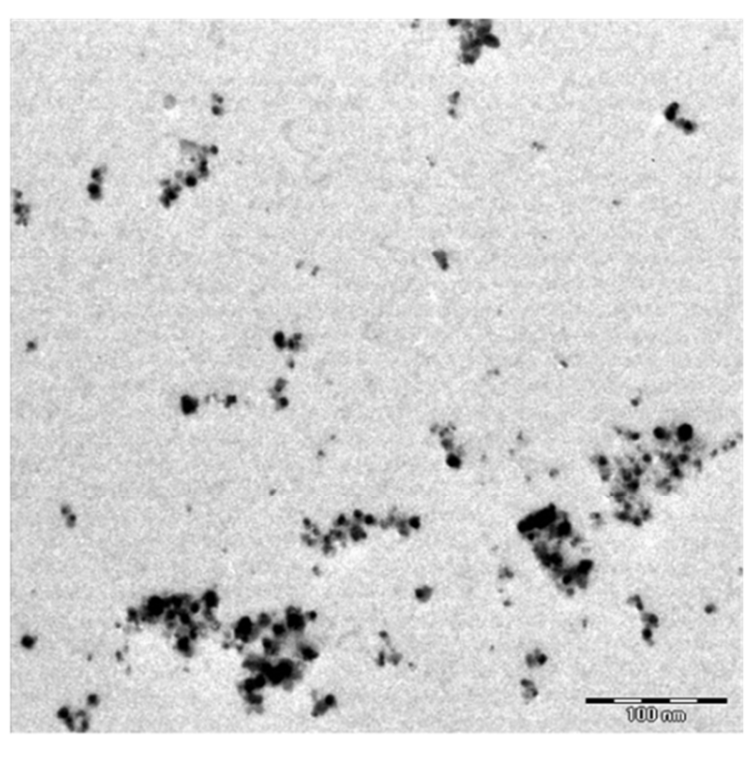

Figure 3. Typical TEM micrograph of NCMC (Ti).

Photodegradations of $\mathrm{MeO}$ and $\mathrm{MeB}$ solutions containing NCMC (Ti) as photocatalyst were analyzed in the $\mathrm{pH}$ value of 1.0, 2.0, 4.4 and 7.2. The relationships between the degradation degree and the $\mathrm{pH}$ value of the solutions under UV lamp and solar irradiation at temperature of $22^{\circ} \mathrm{C}$ and NCMC (Ti) concentration of $0.01 \mathrm{mg} / 1$ are shown in Figure 4 and Figure 5 respectively. These results indicate that a low $\mathrm{pH}$ value can facilitate the decolorization reaction of $\mathrm{MeO}$. It means that the number of $\mathrm{OH}^{*}$ radical increases on the surface of NCMC (Ti) particles in solution by trapping electrons and $\mathrm{H}_{2} \mathrm{O}$ can be absorbed on the NCMC (Ti) surface and reacts with $\mathrm{h}_{\mathrm{VB}}^{+}$in Eq.(3), producing more $\mathrm{OH}^{*}$ radicals under a lower $\mathrm{pH}$ value. It can promote the photogenerated electrons to transfer to the surface of NCMC (Ti) and to react with adsorbed oxygen. Rate of photodegradation processes depends on many factors: type of organic substances, concentration of NCMC (Ti), temperature of solutions and intensity of ultraviolet part of sunlight [3, 17]. For example, rate of photodegradation processes considerably increases with temperature rise. Dependence of this process on sunlight exposure time for $\mathrm{MeB}$ at $30^{\circ} \mathrm{C}$ is given in Figure 5 . 


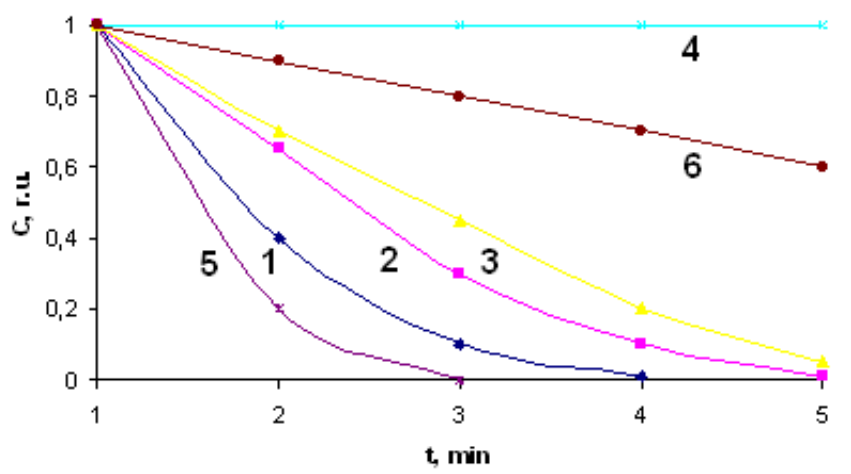

Figure 4. $\mathrm{MeO}$ degradation degree under UV lamp: $\mathrm{pH}=2.2(1), \mathrm{pH}=4.4$ (2), $p H=6.0$ (3) and without NCMC (Ti) (4). MeB degradation degree under UV lamp: $p H=7.2$ (5) and without NCMC (Ti) (6). Concentration of NCMC (Ti) is $0.01 \mathrm{mg} / \mathrm{l}$, temperature of solutions is $22^{\circ} \mathrm{C}$.

The ability in photodegradation of E. Coli and PCBs by NCMC (Ti) were investigated in laboratory condition [17]. Colloidal solution of NCMC (Ti) was added to Petri dishes containing water with $E$. Coli and PCBs, put under the sunlight at $11 \mathrm{am}$ and tested during 6 hours. Concentrations of NCMC (Ti) in mixed solutions were $1 \mu \mathrm{g} / 1$ and $10 \mu \mathrm{g} / \mathrm{l}$. Dependences of bacteria and PCBs concentrations in water samples with temperature of $30^{\circ} \mathrm{C}$ irradiated by sunlight against exposure time are given in Figure 6 and Figure 7. The results show that water is disinfected during about 1 hour and PCBs is degraded during 5-6 hours.

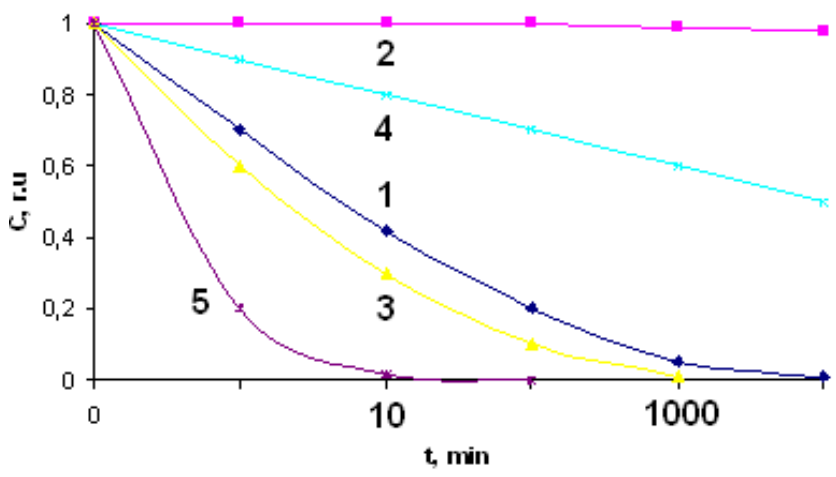

Figure 5. $\mathrm{MeO}$ degradation degree under solar irradiation with (1) and without NCMC (Ti) (2), MeB degradation degree under solar irradiation at $22^{\circ} \mathrm{C}$ (3) and $30^{\circ} \mathrm{C}$ (5) with $\mathrm{NCMC}$ (Ti) and at $22^{\circ} \mathrm{C}$ without nano-photocatalyst (4).

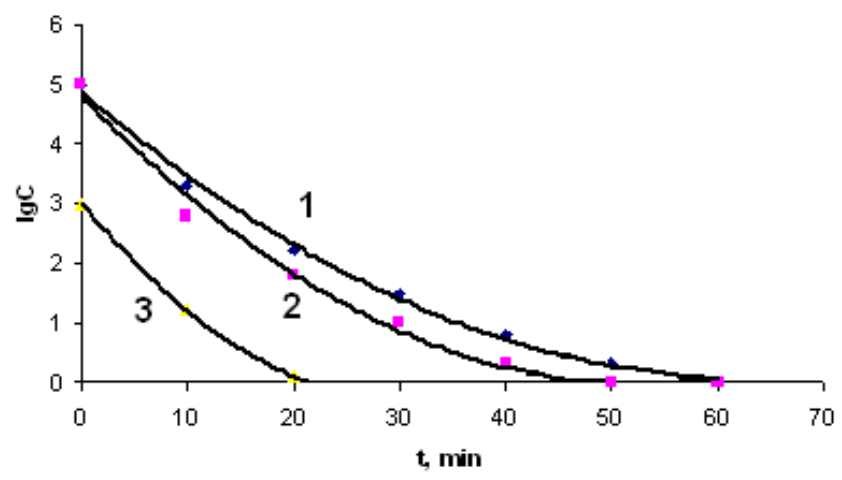

Figure 6. Photodegradation of E. Coli under solar irradiation by NCMC (Ti) with concentration of $1 \mu \mathrm{g} / \mathrm{l}(1)$ and $10 \mu \mathrm{g} / \mathrm{l}(2,3)$. Temperature of solutions is $30^{\circ} \mathrm{C}$.

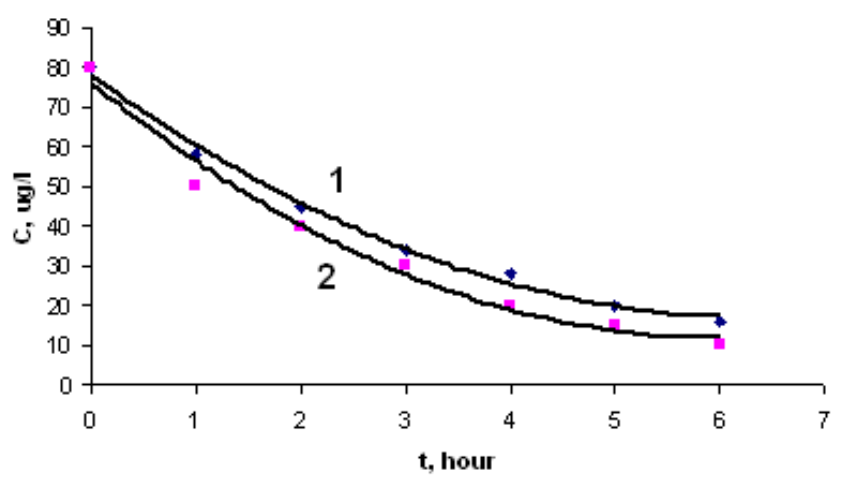

Figure 7. Photodegradation of PCBs under solar irradiation by NCMC (Ti) with concentration of $1 \mu \mathrm{g} / \mathrm{l}(1)$ and $10 \mu \mathrm{g} / \mathrm{l}$ (2). Temperature of solutions is $30^{\circ} \mathrm{C}$.

\section{Conclusion}

Colloidal solutions of electrochemically synthesized NCMC (Ti) have shown a high efficiency as the nanotechnology-based photocatalyst. Photodegradations of $\mathrm{MeO}, \mathrm{MeB}, \mathrm{PCBs}$ and E. Coli go on at NCMC (Ti) concentration of 1-10 $\mu \mathrm{g} / \mathrm{l}$. Time of degradation of organic substances and bacteria under the UV lamp is about 3-5 minutes. Decoloration of $\mathrm{MeO}$ and $\mathrm{MeB}$ under sunlight goes on during 15-60 minutes, killing time of E. Coli is about 10-30 minutes, and destruction time of PCBs is about 6-8 hours. The application of the developed nanotechnology-based photocatalyst for water and wastewater treatment can be appropriate for developing countries or remote sites with no access to electricity.

\section{References}

[1] Y. Boyjoo, et al., A review on photocatalysis for air treatment: from catalyst development to reactor design, Chem. Eng. J. 310 (2017) 537-559.

[2] Y. Lan, Y. Lu, Z. Ren, Mini review on photocatalysis of titanium dioxide nanoparticles and their solar applications, Nano Energy 2 (5) (2013) 1031-1045.

[3] I. T. Garipov, R. R. Khaydarov, O. U. Gapurova, R. A. Khaydarov, I. L. Efimova, S. Yu. Evgrafova. Destruction of organic compounds by nanophotocatalysts. Management of the technosphere, 2019, vol. 2, issue 3, 327-338.

[4] R. A. Khaydarov, R. R. Khaydarov, O. Gapurova. Water purification from metal ions using carbon nanoparticle-conjugated polymer nanocomposites. 2010. Water Research, 44, 1927-1933.

[5] M. Schreck, M. Niederberger, Photocatalytic gas phase reactions, Chem. Mater. 31 (3) (2019) 597-618.

[6] H. Wu, W. P. Fahy, S. Kim, H. Kim, N. Zhao, L. Pilato, A. Kafi, S. Bateman, J. H. Koo Recent developments in polymers/polymer nanocomposites for additive manufacturing, Progress in Materials Science, Volume 111, June 2020, 100638.

[7] P. Ravi, V. Navakoteswara Rao, M. V. Shankar, M. Sathish. $\mathrm{CuOCr}_{2} \mathrm{O}_{3}$ core-shell structured co-catalysts on $\mathrm{TiO}_{2}$ for efficient photocatalytic water splitting using direct solar light. Int J Hydrogen Energy, 43 (2018), pp. 3976-3987. 
[8] C. S. Bryan, O. W. Michael Metal nanoparticle-conjugated polymer nanocomposites. 2005. Chem. Commun. 27, 33753384 .

[9] N. G. Khlebtsov, L. A. Trachuk, A. G. Mel'nikov Sensitivity of Metal Nanoparticle Surface Plasmon Resonance to the Dielectric Environment. 2005, Opt. Spectrosk., 98, 77-86.

[10] H. E. Quinlan, T. Hasan, J. Jaddou, A. J. Hart Industrial and consumer uses of additive manufacturing: a discussion of capabilities, trajectories, and challenges. J Ind Ecol, 21 (2017), pp. S15-S20.

[11] D. Kim et al. Production and characterization of carbon nano colloid via one-step electrochemical method, 2005 J Nanopart Res. 10 (7), 1121-1128.

[12] R. R. Khaydarov, R. A. Khaydarov, O. Gapurova Nanotechnology-Based Photocatalysts: Synthesis and Destruction of Toxic Compounds // Series: Advances in Nanotechnology, Nova Science Publishers, New York, Chapter 3, 8 pages, pp. 33-40, 2016.
[13] GOSSTANDRD. Drinking Water. Hygiene requirements and quality control 1982, GOST 2874-82 of Russian Federation.

[14] K. R. Reddy, M. Hassan, V. G. Gomes, Hybrid nanostructures based on titanium dioxide for enhanced photocatalysis, Appl. Catal. A: Gen. 489 (2015) 116.

[15] M.-Y. Xie, K.-Y. Su, X.-Y. Peng, R.-J. Wu, M. Chavali, W.-C. Chang Hydrogen production by photocatalytic water-splitting on Pt-doped $\mathrm{TiO}_{2}-\mathrm{ZnO}$ under visible light. J Taiwan Inst Chem Eng, 70 (2017), pp. 161-167.

[16] N. Lakshmana Reddy, M. Karthik MVS, Synthesis of Ag- $\mathrm{TiO}_{2}$ nanoparticles for improved photocatalytic hydrogen production under solar light irradiation Adv Porous Mater, 5 (2017), pp. 122-127.

[17] R. A. Khaydarov, R. R. Khaydarov, O. Gapurova Nano-photocatalysts for the destruction of chloro-organic compounds and bacteria in water, 2013, Journal of Colloid and Interface Science. 406, 105-110. 